\title{
Splenophrenic portosystemic shunt in dogs with and without portal hypertension: can acquired and congenital porto-caval connections coexist?
}

\author{
M. Ricciardi* \\ “Pingry" Veterinary Hospital, via Medaglie d'Oro 5, Bari Italy
}

\begin{abstract}
The possible existence of the same pattern of porto-caval connection in dogs having a single congenital portosystemic shunt (CPSS) and in dogs having multiple acquired portosystemic shunt (MAPSS) secondary to portal hypertension $(\mathrm{PH})$ was evaluated. Retrospective evaluation of all CT examinations of patients having portosystemic shunt (PSS) was performed in a 4-year time period. All anomalous porto-caval connections were assessed for anatomical pattern and compared with published veterinary literature. Records of 25 dogs were reviewed. 16 dogs had a single CPSS (CPSS group), and 9 dogs had multiple acquired PSS secondary to PH (APSS group). The splenophrenic shunt pattern was found in 3 dogs of the CPSS group as a single congenital anomaly without PH and in 2 dogs of the APSS group associated with MAPSS and ascites due to different hepatic diseases causing PH. These findings corroborate two hypotheses: 1) Splenophrenic PSS should be considered as a classical CPSS but if this is not sufficient to alleviate a PH developed after birth because of eventual hepatic or portal diseases, in this case ascites and acquired portal collaterals may develop. In this case, MAPSS and CPSS may coexist. 2) The pattern of splenophrenic PSS, classically described among CPSS, may develop as acquired portal collateral in dogs with PH and it should also be included in the category of APSS. These preliminary findings may be helpful in reconsidering the classical haemodynamics of porto-caval diseases, enrich the classification of APSS in dogs and refine the imaging evaluation of patients with PH. Keywords: Computed tomography, Dog, Portal hypertension, Portosystemic shunt.
\end{abstract}

\begin{abstract}
Introduction
Extrahepatic portosystemic shunts (PSS) are abnormal vascular connections between the portal and caval venous systems at the level of their major trunks or secondary branches (Watson and Herrtage, 1998; Nelson and Nelson, 2011). Based on their development and appearances, PSS are classically considered to be distinct, with congenital PSS (CPSS) deriving from embryogenetic errors in the development of vitelline and cardinal venous systems (Ferrell et al., 2003), and acquired PSS (APSS) deriving from recanalization of pre-existing, vestigial embryonic vascular connections between portal and caval systems in the case of portal hypertension (PH) (Fossum, 2002; Szatmàri et al., 2004; Bertolini, 2010a).

In patients with CPSS, clinical signs are related to the mixing of portal blood, which bypasses the hepatic sinusoids, with peripheral venous circulation and include hepatic encephalopathy, stunted growth, cystic calculi, vomiting, and diarrhea (Watson and Herrtage, 1998; Agg, 2006; Kraun et al., 2014). In APSS, clinical signs may be related to the primary underlying disease causing portal flow obstruction with PH or may be due only to PH such as ascites, which is often, but not always, associated (Buob et al., 2011).

Differences in treatment options and prognoses between patients having CPSS and those with APSS
\end{abstract}

make it essential to distinguish between these two conditions but, unfortunately, this cannot be made only on the basis of clinicopathologic findings (Adam et al., 2012).

In this context, non-invasive vascular imaging techniques such as ultrasonography, computed tomography, and magnetic resonance angiography play an important role in detecting pathologic porto-caval connections and defining their origins (Lamb, 1996; Bertolini et al., 2006; Bertolini 2010a, 2010b; Bruehschwein et al., 2010; Nelson and Nelson, 2011; Fukushima et al., 2014).

APSS and CPSS have been described and classified in dogs from an anatomical point of view, using computed tomography angiography (CTA), taking into account their size, origin, course, and termination between portal and caval venous systems (Bertolini et al., 2006; Bertolini, 2010a, 2010b; Nelson and Nelson, 2011; Fukushima et al., 2014; Ricciardi et al., 2014).

It has been reported that in dogs the most consistently observed route of APSSs are left splenogonadal shunt and splenophrenic varices (Szatmàri et al., 2004; Bertolini, 2010a; Ricciardi et al., 2014) while splenocaval, splenophrenic and splenoazygos PSS pattern are reported more frequently among CPSSs (Szatmàri et al., 2004; Bertolini et al., 2006; Nelson and Nelson, 2011; Fukushima et al., 2014). 
In the last few years, different, repeatable but always distinct, vascular patterns have been observed within each category without any overlapping of anatomical pathway between APPS and CPPS. These differences in the course of congenital and acquired PSS allow for their categorization during an angiographic study. To date, few descriptions on the coexistence of APSS and CPSS in the same patient have been published in dogs (Ferrell et al., 2003; Hunt, 2004) but unfortunately they lack a detailed categorization of the shunt phenotype according to the actual anatomical classifications of the of CPSS and APSS. Hence, at present, the coexistence of CPSS in patients having $\mathrm{PH}$, with secondary multiple APSS and ascites, is not fully accepted and still is debated (Ferrell et al., 2003; Szatmári, 2003).

The aim of this retrospective study is to evaluate the possible simultaneous coexistence of the same anatomical pattern of porto-caval connection in dogs having a single CPSS and those having MAPSS.

\section{Material and Methods}

The medical records of all cases of PSS in dogs presented at the "Pingry" Veterinary Hospital in Bari, Italy, between September 2011 and August 2015 were reviewed. Dogs were eligible for inclusion in the study if they fulfilled the following criteria:

1) Complete physical examination, blood count, biochemical profile and urinalysis;

2) Exclusion of right-sided heart failure or severe hypoproteinemia for dogs having ascites;

3) Computed tomography angiography (CTA) of the thoracic and abdominal regions;

4) Confirmation of the vascular anomaly during surgery (for single PSS) and a histopathologic or surgical confirmation of the cause of $\mathrm{PH}$ (for patients with multiple PSS).

Multidetector Computed Tomography examination protocol

All CTA were acquired using a 16-slice multidetector computed tomography (MDCT) scanner (Somatom Emotion, Siemens, Forchheim, Germany) before and after the manual injection of iodinate contrast medium (640 mg I/kg; Iopamigita ${ }^{\circledR}$ Insight Agents GmbHR, Heildeberg, Germany). Scanning and reconstruction parameters were as follows: helical modality, 0.6 - 1 sec/gantry rotation, $1 \mathrm{~mm}$ slice thickness; $180 \mathrm{kV}, 110$ mAs; soft tissue reconstruction algorithm.

\section{MDCT image analysis}

For selected patients, MDCT data were retrieved and restored from picture archiving and communication systems (PACS) (Marcel van Herk, "Conquest DICOM software." Online Available: http://ingenium.home.xs4all.nl/dicom.html.), and carefully assessed by the author for thoracic and abdominal vascular anomalies. Multiplanar reformatted images and volume rendered angiographic reconstructions were obtained from native $\mathrm{CT}$ images, using a dedicated post-processing software (OsiriX DICOM-viewer; Pixmeo, Geneva, Switzerland). Information extracted from CTA of each dog included in the study comprised number of PSS (single or multiple), size (large shunt or varices), pattern of PSS (according to the major classifications of CPSS (Szatmàri et al., 2004; Bertolini, 2010b; Nelson and Nelson, 2011; Fukushima et al., 2014) and APSS (Bertolini, 2010a), presence/absence of abdominal effusion (ascites), and presence of macroscopic structural cause of portal flow obstruction.

\section{Histopathologic evaluation}

All liver biopsy samples in dogs, with suspected PH, were obtained by exploratory laparotomy. Specimens were sent for histopathologic evaluation in a certified veterinary laboratory (San Marco Veterinary Laboratory, Padova, Italy). All histopathological evaluations were made by board certified pathologists.

\section{Results}

The medical records of 25 dogs with PSS matched the inclusion criteria and were reviewed.

16 dogs had a single PSS shunt without abdominal effusion. Regarding the anatomical pattern there were 7 splenocaval, 4 right gastric-caval, 2 splenoazygos and 3 splenophrenic PSS.

In Table 1, clinical signs, hematobiochemical and urinalysis abnormalities, and PSS pattern are summarized individually for each dog of this group. The final diagnosis for all these dogs was single congenital PSS.

Nine dogs had multiple PSS. In this group, 8 dogs had concomitant abdominal effusion and no structural nor attenuation changes of the liver were evident on CT images. In one dog, CT showed multiple hepatic masses suggestive of diffuse hepatic neoplasia, absence of abdominal effusion, and multiple large porto-caval connections. Two large vessels, originating respectively from the pancreaticoduodenal vein and from splenic vein, ran ventro-caudally and joined in a single vessel draining into the caudal vena cava at level of right gonadal vein (Table 2 - Fig. 1, dog 5).

The other porto-caval connection was a left splenogonadal shunt (Fig. 2). Hepatic lesions were diagnosed histopathologically as histiocytic sarcoma. One dog with multiple PSS had a large shunt between portal vein and cranial vena cava via left internal thoracic vein (Table 2 - Fig. 3, dog 1). In one dog multiple tangled large shunts were found between the main trunk of portal vein at level of splenic vein insertion and the pre-hepatic segment of the caudal vena cava (Table 2 - Fig. 4 , dog 7).

All dogs had a final diagnosis of $\mathrm{PH}$ with multiple APSS based on clinical, CT and histopathologic findings. In 8 dogs $\mathrm{PH}$ was due to hepatic microvascular or parenchymal disorder based on evaluation of liver biopsy samples. 
Table 1. Signalment, clinical signs, major hematobiochemical and urinalysis abnormalities and shunt pattern in dogs with CPSS.

\begin{tabular}{|c|c|c|c|c|}
\hline $\mathrm{n}$ & Signalment & Clinical signs & $\begin{array}{c}\text { Pattern of CPSS evident } \\
\text { on CTA }\end{array}$ & $\begin{array}{l}\text { Major hematobiochemical and } \\
\text { urinalysis abnormalities }\end{array}$ \\
\hline 1 & $\begin{array}{l}\text { 9-years-old, female, } \\
\text { Yorkshire Terrier }\end{array}$ & $\begin{array}{l}\text { Abnormal mentation; } \\
\text { vomiting }\end{array}$ & Right gastric-caval shunt & $\begin{array}{l}\text { ALT (UI/L): } 150 \text { (20-70); UBA } \\
(\mathrm{mmol} / \mathrm{L}): 157(1-12.5)\end{array}$ \\
\hline 2 & $\begin{array}{l}\text { 10-years-old, male, } \\
\text { Yorkshire Terrier }\end{array}$ & $\begin{array}{l}\text { Seizures; abnormal } \\
\text { mentation; vomiting }\end{array}$ & Left gastric-azygos shunt & UBA (mmol/L): 70 (1-12.5) \\
\hline 3 & $\begin{array}{l}\text { 1-year-old, male, } \\
\text { Mongrel }\end{array}$ & $\begin{array}{l}\text { Abnormal mentation; } \\
\text { vomiting }\end{array}$ & Spleno-caval shunt & $\begin{array}{l}\text { ALT (UI/L): } 86 \text { (20-70); UBA } \\
\text { (mmol/L): } 98 \text { (1-12.5) }\end{array}$ \\
\hline 4 & $\begin{array}{l}\text { 5-years-old, female, } \\
\text { Pinscher }\end{array}$ & $\begin{array}{l}\text { Abnormal mentation; } \\
\text { mild hematuria }\end{array}$ & Splenophrenic shunt & $\begin{array}{l}\text { AST (UI/L): } 179 \text { (20-50); ALT } \\
\text { (UI/L): } 230 \text { (20-70); Albumin } \\
\text { (g/dL): } 2.4(2.5-4.0) ; \text { UBA } \\
\text { (mmol/L): } 400(1-12.5)\end{array}$ \\
\hline 5 & $\begin{array}{l}\text { 5-years-old, female, } \\
\text { Beagle }\end{array}$ & $\begin{array}{l}\text { Polyuria and polydipsia; } \\
\text { hematuria. }\end{array}$ & Right gastric-caval shunt & UBA (mmol/L): $336(1-12.5)$ \\
\hline 6 & $\begin{array}{l}\text { 8-months-old, female, } \\
\text { Yorkshire Terrier }\end{array}$ & Seizures; disappetence & Splenophrenic shunt & $\begin{array}{l}\text { AST (UI/L): } 135 \text { (20-50); ALT } \\
\text { (UI/L): } 112(20-70) ; \text { UBA } \\
\text { (mmol/L): } 27(1-12.5)\end{array}$ \\
\hline 7 & $\begin{array}{l}\text { 11-years-old, male, } \\
\text { Shih-tzu }\end{array}$ & Abnormal mentation & Right gastric-caval shunt & $\begin{array}{l}\text { Albumin (g/dL): } 2.0(2.5-4.0) \\
\text { UBA (mmol/L): } 363(1-12.5)\end{array}$ \\
\hline 8 & $\begin{array}{l}\text { 1-year-old, female, } \\
\text { Pinscher }\end{array}$ & $\begin{array}{l}\text { Seizures; abnormal } \\
\text { mentation; depression }\end{array}$ & Spleno-caval shunt & $\begin{array}{l}\text { Albumin }(\mathrm{g} / \mathrm{dL}): 1.6(2.5-4.0) \\
\text { UBA (mmol/L): } 144(1-12.5)\end{array}$ \\
\hline 9 & $\begin{array}{l}\text { 3-years-old, female, } \\
\text { Yorkshire Terrier }\end{array}$ & $\begin{array}{l}\text { Abnormal mentation; } \\
\text { disappetence; vomiting }\end{array}$ & Spleno-caval shunt & $\begin{array}{l}\text { Albumin }(\mathrm{g} / \mathrm{dL}): 2.0(2.5-4.0) \\
\text { UBA }(\mathrm{mmol} / \mathrm{L}): 213(1-12.5)\end{array}$ \\
\hline 10 & $\begin{array}{l}\text { 2-years-old, male, } \\
\text { Chihuahua }\end{array}$ & $\begin{array}{l}\text { Abnormal mentation; } \\
\text { lethargy }\end{array}$ & Splenophrenic shunt & UBA (mmol/L): 30 (1-12.5) \\
\hline 11 & $\begin{array}{l}\text { 4-years-old, female, } \\
\text { Yorkshire Terrier }\end{array}$ & $\begin{array}{l}\text { Hematuria; disappetence; } \\
\text { vomiting }\end{array}$ & Left gastric-azygos shunt & $\begin{array}{l}\text { Albumin (g/dL): } 2.1(2.5-4.0) \\
\text { UBA (mmol/L): } 161(1-12.5)\end{array}$ \\
\hline 12 & $\begin{array}{l}\text { 6-months-old, male, } \\
\text { Mongrel }\end{array}$ & $\begin{array}{l}\text { Abnormal mentation; } \\
\text { depression; vomiting; }\end{array}$ & Spleno-caval shunt & $\begin{array}{l}\text { Albumin (g/dL): } 2.0(2.5-4.0) ; \\
\text { UBA (mmol/L): } 182(1-12.5)\end{array}$ \\
\hline 13 & $\begin{array}{l}\text { 3-months-old, female, } \\
\text { Florence Spitz }\end{array}$ & $\begin{array}{l}\text { Abnormal mentation; } \\
\text { vomiting }\end{array}$ & Spleno-caval shunt & UBA (mmol/L): $102(1-12.5)$ \\
\hline 14 & $\begin{array}{l}\text { 5-months-old, female, } \\
\text { Pinscher }\end{array}$ & Vomiting; lethargy & Right gastric-caval shunt & $\begin{array}{l}\text { ALT (UI/L): } 90 \text { (20-70); UBA } \\
\text { (mmol/L): } 159(1-12.5)\end{array}$ \\
\hline 15 & $\begin{array}{l}\text { 1-year-old, male, } \\
\text { Mongrel }\end{array}$ & Abnormal mentation & Spleno-caval shunt & UBA (mmol/L): 49 (1-12.5) \\
\hline 16 & $\begin{array}{l}\text { 7-months-old, male, } \\
\text { Mongrel }\end{array}$ & $\begin{array}{l}\text { Seizures; depression; } \\
\text { vomiting }\end{array}$ & Spleno-caval shunt & $\begin{array}{l}\text { Albumin }(\mathrm{g} / \mathrm{dL}): 2.2(2.5-4.0) \\
\text { UBA (mmol/L): } 173(1-12.5)\end{array}$ \\
\hline
\end{tabular}

In one dog the increased portal flow and subsequent $\mathrm{PH}$ was due to a large extra-hepatic arteriovenous fistula in which the hepatic artery joined the portal vein. In each dog with acquired portal collaterals there were both large PSS and small varices. Clinical signs, hematobiochemical and urinalysis abnormalities, histopathologic findings and APSS patterns are summarized in Table 2.

Five dogs had a large porto-caval connection between the left gastric vein and the post hepatic segment of caudal vena cava at the phrenic vein level. In 3 of these 5 patients (Table 1: $\operatorname{dog} 4,6,10$ ) the extrahepatic splenophrenic PSS was found as a single porto-caval connection and no abdominal effusion was present (Fig. 5). In the other two dogs (Table 2: dog 1, 2) the extrahepatic splenophrenic PSS was associated with multiple APSS and ascites (which developed as a consequence of PH due to primary liver disease i.e. primary hypoplasia of the portal vein and lobular dissecting hepatitis) (Fig. 6 and 7).

\section{Discussion}

In veterinary literature simultaneous congenital and acquired PSS have been reported in three dogs (Ferrell et al., 2003; Hunt, 2004). In two of these cases the vascular anomalies and their anatomical pattern were not assessed (Ferrell et al., 2003) and not available for review (Hunt, 2004). In one of these 3 dogs the coexistence of CPSS and APSS has been hypothesized because of the presence of a large venous connection between splenic vein and post-hepatic caudal vena cava, multiple porto-caval collaterals near the left kidney and histologic liver findings similar to those found with congenital shunts (Ferrell et al., 2003). However, this condition is not fully accepted by veterinary specialists and is still debated. (Szatmári, 2003). 

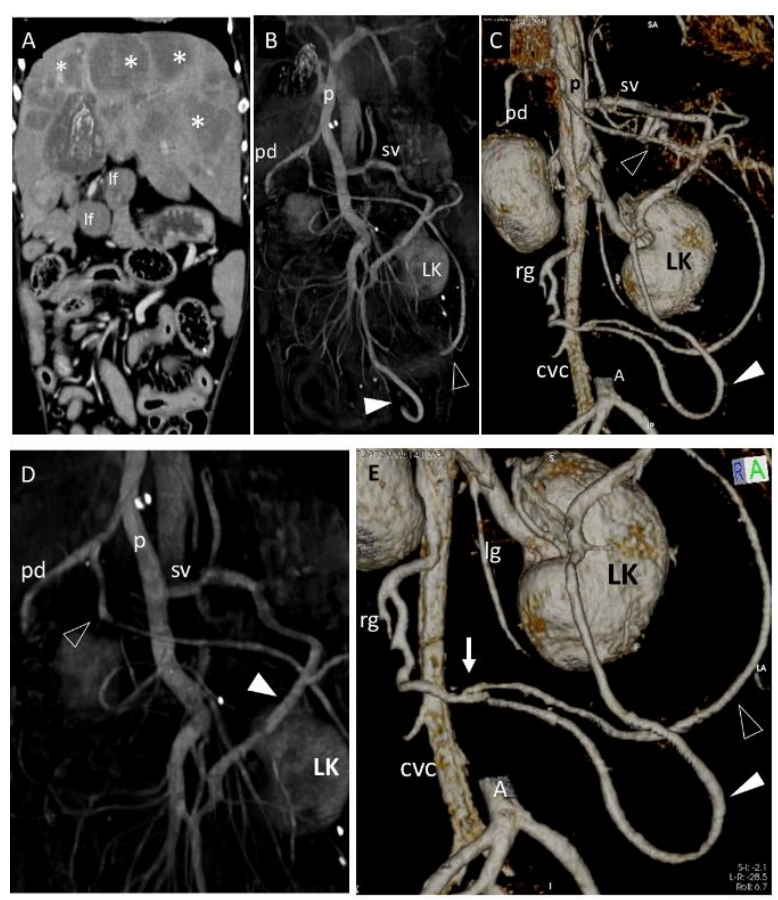

Fig. 1. Dog 5 of PH group. (A) Dorsal contrast-enhanced multiplanar reformatted CT image of the abdomen. There are multiple hepatic neoformations (asterisks) ipoattenuating to hepatic parenchyma, periportal lymph nodes enlargement (lf) and no abdominal effusion. (B,C,D,E) Three-dimensional volume rendered image of the portal vein $(\mathrm{p})$ and caudal vena cava (CVC) - ventral views. Two large vessels (empty and full arrowheads) originate respectively from the pancreaticoduodenal vein (pd) and from splenic vein (sv), run caudally and join in a single vessel draining into the caudal vena cava at level of right gonadal vein (rg). (B) whole portal vein, ventral view; (C) detail of the entire PSS from its double portal origin to its caval termination; (D) detail of origins of the anomalous vessels from pancreaticoduodenal vein (empty arrowhead) and splenic vein (full arrowhead); (E) detail of connection (arrow) of the two shunts in one vessel which enters caudal vena cava at level of right gonadal vein. These vessels appeared suggestive of APSS because they were associated with a visible cause of PH (diffuse hepatic neoplasia) and other classical APSS (see Fig. 5). The absence of ascites could be explained by a complete effectiveness of these APSS in alleviating portal pressure. LK, left kidney; lg, left gonadal vein; A, caudal abdominal aorta (sectioned and partially removed).

The possibility of the coexistence of congenital and acquired PSS in the same patient is considered unlikely for different reasons:

1) APSS may be small tortuous vessels, defined as varices, but may also be found as large vessels (Bertolini, 2010a; Ricciardi et al., 2014). Hence, if a large PSS is found together with other multiple small tortuous porto-caval connections, it is conceivable that all these abnormal vessels might be acquired PSS.
2) According to hemodynamic principles the presence of a CPSS, in a dog with portal flow obstruction at level of the liver, would bypass portal blood in the systemic (caval) circulation that presents the lowest resistance, making development of PH unlikely (Szatmári, 2003). The presence of ascites should be considered incompatible with a CPSS (Wrigley et al., 1987; Szatmari and Rothuizen, 2002) and such a finding, in non-cardiac, non-hypoalbuminemic patients, should prompt recognition of a likely diagnosis of APSS secondary to PH (Adam et al., 2012).

3) Histopathologic liver changes may be identical in case of primary diseases causing PH (idiopathic non-cirrhotic PH, portal venous hypoplasia, hepatic microvascular dysplasia and congenital arterioportal fistula) or in the case of reduced portal perfusion (congenital PSS). Thus differentiation between APSS due to primary liver disease and CPSS may not be possible based on liver histopathologic findings (Van den Ingh et al., 1995a, 1995b; Center, 1996; Bunch et al., 2001).

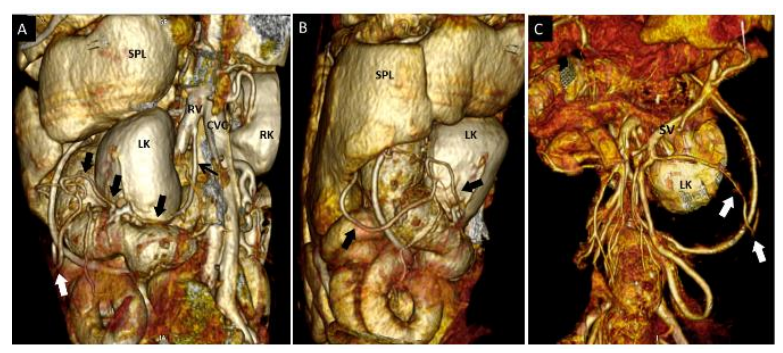

Fig. 2. Dog 5 of $\mathrm{PH}$ group. Three-dimensional volumerendered CT angiography of the left splenogonadal PSS. (A) dorso-lateral view; (B) left lateral view; (C) ventral view. From left gonadal vein (A, black arrow) a tortuous vessel (thick arrows) runs in caudo-ventro-lateral direction to join the splenic vein (SV). As shown in Fig. 1, splenic vein drained into right gonadal vein. SPL, spleen; LK, left kidney; RK, right kidney. This dog had both classified and unclassified APSS.

It has been demonstrated that signalment, clinical signs, and results of biochemical analysis would be unlikely to enable differentiation between dogs with congenital and acquired PSS (Hunt, 2004; Adam et al., 2012). Currently, advanced diagnostic imaging and physical examination (detection of ascites) are considered the most reliable means of discrimination between acquired and congenital PSS in dogs (Szatmári, 2003). In major classifications of APSS and CPSS different patterns have been codified using MDCT angiography and their morphology appear constant and repeatable in all the different reported cases (Szatmàri et al., 2004; Bertolini, 2010a, 2010b; Nelson and Nelson, 2011; Fukushima et al., 2014; Ricciardi et al., 2014). 
Table 2. Clinical, imaging, hematobiochemical/urinalysis and histopathologic findings in dogs with PH and APSS. Asterisks indicate unclassified APSS patterns.

\begin{tabular}{|c|c|c|c|c|c|c|}
\hline $\mathrm{n}$ & Signalment & Clinical signs & $\begin{array}{c}\text { Abdominal } \\
\text { effusion }\end{array}$ & $\begin{array}{c}\text { Pattern of APSS evident on CTA } \\
\text { according to major classification [4] }\end{array}$ & $\begin{array}{l}\text { Hematobiochemical and } \\
\text { urinalysis abnormalities }\end{array}$ & $\begin{array}{c}\text { Histopathologic } \\
\text { diagnosis }\end{array}$ \\
\hline 1 & $\begin{array}{l}\text { 6-months- } \\
\text { old, female, } \\
\text { Rottweiler }\end{array}$ & $\begin{array}{l}\text { Abdominal } \\
\text { distension; } \\
\text { inappetence }\end{array}$ & $\begin{array}{l}\text { Pure } \\
\text { transudate }\end{array}$ & $\begin{array}{l}\text { - Gastro-phrenic varices; } \\
\text { - Large shunt between colic vein and } \\
\text { right internal iliac vein; } \\
\text { - Large shunt between portal vein and } \\
\text { left internal thoracic vein*; } \\
\text { - Large shunt between left gastric vein } \\
\text { and phrenic vein* (Splenophrenic } \\
\text { shunt) }\end{array}$ & $\begin{array}{l}\text { AST (UI/L): } 77(20-50) ; \\
\text { ALP (UI/L): } 4797(50-200) ; \\
\text { Albumin (g/dL): } 2.4(2.5-4.0) \\
\text { UBA (mmol/L): } 160(1-12.5)\end{array}$ & $\begin{array}{l}\text { PHPV (primary } \\
\text { hypoplasia of } \\
\text { the portal vein) }\end{array}$ \\
\hline 2 & $\begin{array}{l}\text { 1-year-old, } \\
\text { male, } \\
\text { Maltese }\end{array}$ & $\begin{array}{l}\text { Abdominal } \\
\text { distension; } \\
\text { inappetence }\end{array}$ & $\begin{array}{l}\text { Pure } \\
\text { transudate }\end{array}$ & $\begin{array}{l}\text { - Gastro-phrenic varices; } \\
\text { - Mesenteric collaterals (Large shunt } \\
\text { between left colic vein and left } \\
\text { gonadal vein); } \\
\text { - Large shunt between left gastric vein } \\
\text { and phrenic vein* (Splenophrenic } \\
\text { shunt) }\end{array}$ & $\begin{array}{l}\text { AST (UI/L): } 226(20-50) ; \\
\text { ALT (UI/L): } 175 \text { (20-70); } \\
\text { UBA (mmol/L): } 160(1-12.5)\end{array}$ & $\begin{array}{l}\text { Lobular } \\
\text { dissecting } \\
\text { hepatitis }\end{array}$ \\
\hline 3 & $\begin{array}{l}\text { 4-months- } \\
\text { old, male, } \\
\text { Mongrel }\end{array}$ & $\begin{array}{l}\text { Abdominal } \\
\text { distension; } \\
\text { Drowsiness; } \\
\text { Vomiting; } \\
\text { Diarrhea }\end{array}$ & $\begin{array}{l}\text { Pure } \\
\text { transudate }\end{array}$ & Gastro-phrenic varices & $\begin{array}{l}\text { AST (UI/L): } 46 \text { (20-50); } \\
\text { ALT (UI/L): } 231(20-70) ; \\
\text { Albumin (g/dL): } 1.9(2.5-4.0) \\
\text { UBA (mmol/L): } 82(1-12.5)\end{array}$ & PHPV \\
\hline 4 & $\begin{array}{l}\text { 7-months- } \\
\text { old, female, } \\
\text { Mongrel }\end{array}$ & $\begin{array}{l}\text { Abdominal } \\
\text { distension }\end{array}$ & $\begin{array}{l}\text { Pure } \\
\text { transudate }\end{array}$ & $\begin{array}{l}\text { - Gastro-phrenic varices; } \\
\text { - Left splenogonadal shunt (large } \\
\text { shunt between splenic vein and left } \\
\text { gonadal vein) }\end{array}$ & $\begin{array}{l}\text { AST (UI/L): } 79(20-50) ; \\
\text { UBA (mmol/L): } 89(1-12.5)\end{array}$ & PHPV \\
\hline 5 & $\begin{array}{l}\text { 12-years-old, } \\
\text { female, } \\
\text { Mongrel }\end{array}$ & $\begin{array}{l}\text { Weight loss; } \\
\text { Vomiting; } \\
\text { Diarrhea }\end{array}$ & None & $\begin{array}{l}\text { - Left splenogonadal shunt; } \\
\text { - Large shunt between } \\
\text { pancreaticoduodenal vein, splenic } \\
\text { vein and right gonadal vein* }\end{array}$ & $\begin{array}{l}\text { ALT (UI/L): } 320(20-70) ; \\
\text { ALP (UI/L): } 938 \text { (50-200); } \\
\text { Fibrinogen (mg/dL): } 145 \\
(152-184) \\
\text { FSPs }(\mu \mathrm{g} / \mathrm{mL}): 17(0.11- \\
2.84)\end{array}$ & $\begin{array}{l}\text { Diffuse hepatic } \\
\text { neoplasia } \\
\text { (histiocytic } \\
\text { sarcoma) }\end{array}$ \\
\hline 6 & $\begin{array}{l}\text { 2-years-old, } \\
\text { female, } \\
\text { German } \\
\text { shepherd }\end{array}$ & $\begin{array}{l}\text { Weight loss; } \\
\text { Abdominal } \\
\text { distension; } \\
\text { Abnormal } \\
\text { mentation; } \\
\text { inappetence }\end{array}$ & $\begin{array}{l}\text { Pure } \\
\text { transudate }\end{array}$ & $\begin{array}{l}\text { - Gastro-phrenic varices; } \\
\text { - Left splenogonadal shunt }\end{array}$ & $\begin{array}{l}\text { AST (UI/L): } 109 \text { (20-50); } \\
\text { ALT (UI/L): } 214(20-70) ; \\
\text { UBA (mmol/L): } 133(1-12.5)\end{array}$ & PHPV \\
\hline 7 & $\begin{array}{l}\text { 4-months- } \\
\text { old, male, } \\
\text { Great dane }\end{array}$ & $\begin{array}{l}\text { Weight loss; } \\
\text { Abdominal } \\
\text { distension; } \\
\text { inappetence }\end{array}$ & $\begin{array}{l}\text { Pure } \\
\text { transudate }\end{array}$ & $\begin{array}{l}\text { - Gallbladder varices; } \\
\text { - Gastro-phrenic varices; } \\
\text { - Left splenogonadal shunt; } \\
\text { - multiple, tangled, large shunts } \\
\text { between portal vein (main trunk at } \\
\text { level of splenic vein insertion) and } \\
\text { caudal vena cava (main trunk - pre- } \\
\text { hepatic segment)* }\end{array}$ & $\begin{array}{l}\text { AST (UI/L): } 93 \text { (20-50); } \\
\text { ALT (UI/L): } 342(20-70) ; \\
\text { Albumin (g/dL): } 2.4(2.5-4.0) \\
\text { UBA (mmol/L): } 166(1-12.5)\end{array}$ & $\begin{array}{l}\text { Large extra- } \\
\text { hepatic artero- } \\
\text { portal fistula }\end{array}$ \\
\hline 8 & $\begin{array}{l}\text { 1-year-old, } \\
\text { female, Pit } \\
\text { Bull Terrier }\end{array}$ & $\begin{array}{l}\text { Weight loss; } \\
\text { Abdominal } \\
\text { distension }\end{array}$ & $\begin{array}{l}\text { Pure } \\
\text { transudate }\end{array}$ & $\begin{array}{l}\text { - Gastro-phrenic varices } \\
\text { - Left splenogonadal shunt (large } \\
\text { shunt between splenic vein and left } \\
\text { gonadal vein) }\end{array}$ & $\begin{array}{l}\text { AST (UI/L): } 1081(20-50) ; \\
\text { ALT (UI/L): } 1645(20-70) ; \\
\text { Albumin (g/dL):1.5 (2.5-4.0) } \\
\text { UBA (mmol/L): } 1282.4(1- \\
12.5)\end{array}$ & PHPV \\
\hline 9 & $\begin{array}{l}\text { 9-months- } \\
\text { old, male, } \\
\text { Mongrel }\end{array}$ & $\begin{array}{l}\text { Abdominal } \\
\text { distension }\end{array}$ & $\begin{array}{l}\text { Pure } \\
\text { transudate }\end{array}$ & $\begin{array}{l}\text { - Gastro-phrenic varices } \\
\text { - Colic varices } \\
\text { - Left splenogonadal shunt }\end{array}$ & $\begin{array}{l}\text { AST (UI/L): } 57(20-50) \\
\text { UBA (mmol/L): } 339(1-12.5)\end{array}$ & $\begin{array}{l}\text { End-stage } \\
\text { chronic } \\
\text { hepatitis }\end{array}$ \\
\hline
\end{tabular}

To date, codified CPSS patterns have not been reported in dogs with $\mathrm{PH}$ and, vice versa, codified APSS patterns have never been reported as single shunt without ascites. Thus, the evaluation of the size, number and anatomical pattern of a PSS as seen on CT images, along with the presence or absence of abdominal effusion, may be helpful for the categorization of the PSS type (Szatmàri et al., 2004; Bertolini, 2010a, 2010b; Nelson and Nelson, 2011; Fukushima et al.,
2014; Ricciardi et al., 2014).

The clinical relevance of the differentiation between CPPS and APSS patterns derives from the necessity to distinguish patients with underlying $\mathrm{PH}$ (testified by the presence of MAPSS), for which shunt closure is not indicated and that require further investigations in order to diagnose the cause of the hypertensive disorder, from patients with congenital porto-caval connections which require surgical closure. 


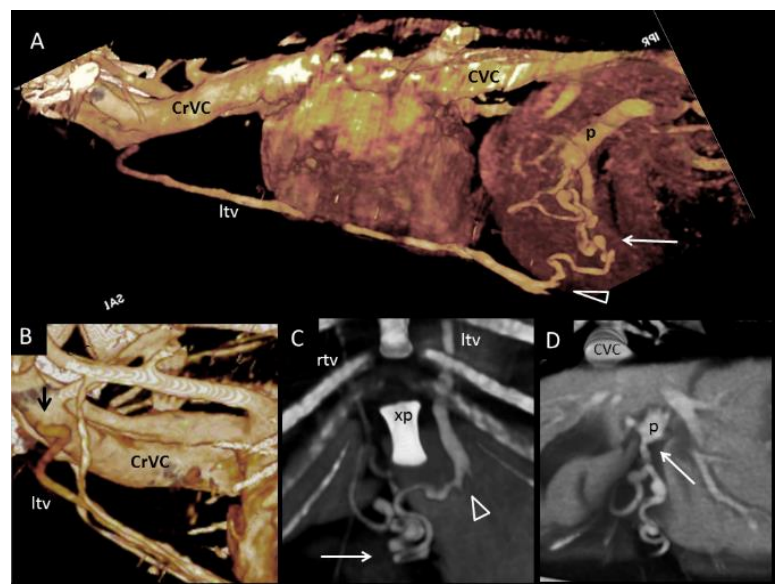

Fig. 3. Dog 1 of PH group; APSS from portal vein to cranial vena cava via left internal thoracic vein. (A) Threedimensional volume-rendered CT angiography of cranial abdomen and thorax. A Tortuous vessel (long arrow) originates from the portal vein (p) before its intra-hepatic branches, courses ventrally and joins the left internal thoracic vein (ltv) to reach cranial vena cava (CrVC). (B) Threedimensional volume-rendered detail of left internal thoracic vein origin (ltv) (black arrow) from cranial vena cava (CrVC). (C) Ventral three-dimensional volume-rendered image at level of xiphoid process of the sternum (xp) showing in detail the point of connection (arrowhead) between the PSS (long arrow) and left internal thoracic vein (ltv). (D) Transverse three-dimensional volume-rendered image at level of portal vein just before its intrahepatic division. The long arrow points to the PSS origin from the portal vein. rtv, right internal thoracic vein; CVC, caudal vena cava.

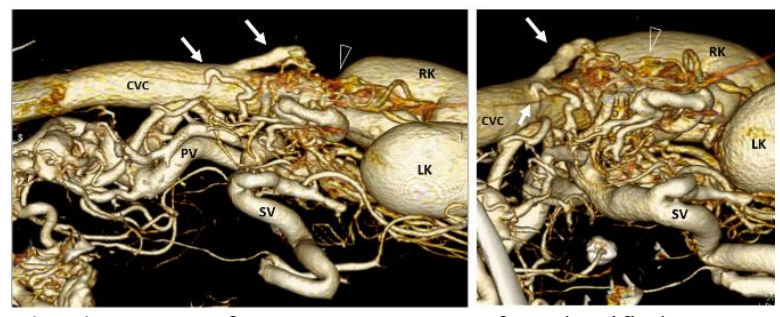

Fig. 4. Dog 7 of PH group. APSS of unclassified pattern. Three-dimensional volume-rendered CT angiography of portal vein and caudal vena cava. (A) Left lateral view; (B) detail of caudal vena cava (CVC) - dorso-cranial view. Two large vessels (arrows) originating at different points from portal vein (PV) drained into main trunk of caudal vena cava just cranially to the kindeys. Gastrophrenic varices are also evident (arrowheads). LK, left kidney; RK, right kidney.

Among the cases examined in this study, 5 dogs had a large extrahepatic PSS attributable to the splenophrenic pattern. This shunt type has been classified among CPSS (Bertolini, 2010b, Nelson and Nelson, 2011) and in a study on 178 cases of congenital extra-hepatic PSS it has been described as one of the most common anatomical patterns (Fukushima et al., 2014). However, a splenophrenic PSS pattern has never been reported among APSS (Bertolini, 2010a).

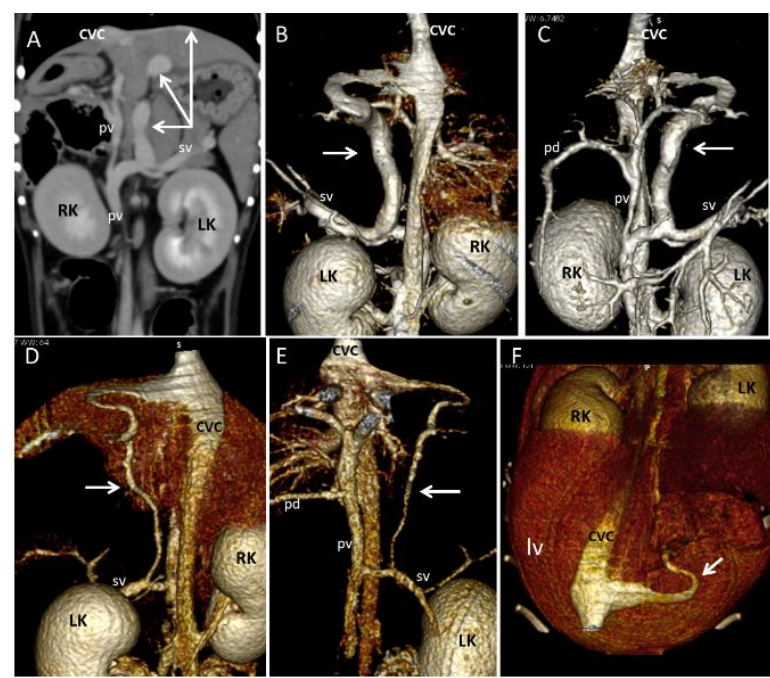

Fig. 5. Splenophrenic PSS in $\operatorname{dog} 4$ (A, B, C) and dog 10 (D, E, F) of CPSS group. (A) Dorsal multiplanar reformatted CT image of the abdomen at level of kidneys. A Splenophrenic PSS is evident (arrows) between splenic vein (sv) and posthepatic segment of caudal vena cava (CVC). No varices nor abdominal effusion are evident. Three-dimensional volumerendered CT angiography of portal system and caudal vena cava in dogs 4 and 10. (B, D - Dorsal views; C,E - ventral views; $\mathrm{F}$ - dorso-cranial view at level of hepatic surface.). On three-dimensional volume-rendered CT angiography of portal system and caudal vena cava of both dogs the splenophrenic PSS (arrows) had same anatomical pattern seen in dogs with PH of Fig. 1 and 2. These PSS were assumed to be congenital because appear as single porto-caval connections not associated with ascites or varices, and no structural causes of portal flow obstruction were evident on CT images.

In three out of 5 of our dogs the splenophrenic PSS was single and not associated with ascites so it was considered most likely a CPSS. However, in the other two of these 5 dogs the splenophrenic PSS was associated with PH, due to PHPV (Table $2-\operatorname{dog} 1)$ and lobular dissecting hepatitis (Table $2-\operatorname{dog} 2$ ), with multiple APSS and abdominal effusion.

Based on these findings, for both cases two hypothesis were made:

1) Coexistence of CPSS of splenophrenic pattern and multiple APSS in these two patients with PH. In this case, a CPSS may be not sufficient to alleviate PH caused by primary diffuse intrahepatic microvascular or parenchymal disease. Consequently, APSS and ascites develop (Szatmári, 2003). This hypothesis would disavow the theory that development of $\mathrm{PH}$ is unlikely in the presence of a CPSS, as previously reported (Szatmári, 2003), and would help refine imaging evaluation of patients with $\mathrm{PH}$.

2) The splenophrenic PSS may also be a pattern of APSS until now unreported, which regains patency if $\mathrm{PH}$ develops. The portal vein in the normal dog 
has at least three embryonic connections with the systemic venous system, which usually are not, or only minimally perfused. One of these connects the phrenic vein with small branches of the portal vein (Huntington and Mcclure, 1920; Bertolini, 2010a). Such embryonic pathways of porto-caval connection may develop in splenophrenic APSS when PH occurs.
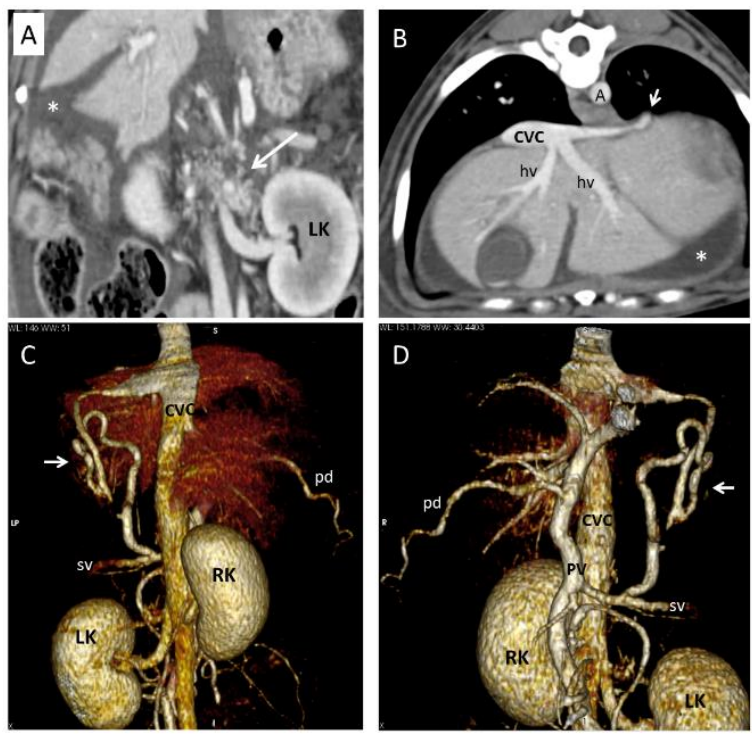

Fig. 6. Dog 1 of $\mathrm{PH}$ group. (A) Dorsal multiplanar reformatted CT image of abdomen at level of kidneys. Gastrophrenic varices (long arrow) are visible medially to the left kidney (LK). Large amount of fluid (ascites) is evident in background (asterisk). (B) Transverse multiplanar reformatted CT image of abdomen at level of liver and insertion of phrenic vein. Short arrow indicates insertion of a PSS in caudal vena cava (CVC). (C) Dorsal and (D) ventral three-dimensional volume-rendered $\mathrm{CT}$ angiography of portal system and caudal vena cava. Short arrows point to splenophrenic shunt. A, aorta; RK, right kidney; PV, portal vein; pd, pancreaticoduodenal vein; sv, splenic vein.

If splenophrenic PSS represents a pattern shared by both APSS and CPSS, categorization of the vascular anomaly based only on imaging findings may be challenging. In this case diagnosis may be influenced by the presence or absence of abdominal effusion as a frequent distinctive hallmark between $\mathrm{PH}$ or congenital vascular anomaly. Interestingly, in one dog with $\mathrm{PH}$ secondary to diffuse hepatic histiocytic sarcoma (Table 2, dog 5), CT showed multiple large porto-caval connections (of both classified and unclassified anatomical patterns) but no abdominal effusion (Fig. 1 and 2). In this dog the presence of multiple portal collaterals with one left splenogonadal shunt (which until now has never been reported among CPSS) and imaging findings compatible with diffuse hepatic neoplasia, suggested a presumptive diagnosis of $\mathrm{PH}$ with APSS. In this case the absence of ascites could be explained by the complete effectiveness of the APSS in alleviating portal pressure. However, in cases of primary microvascular or parenchymal hepatic disorders macroscopically undetectable on imaging evaluation (such as PHPV), the possible absence of ascites and the presence of a single acquired splenophrenic shunt (without other MAPSS) may disorient the presumptive diagnosis of $\mathrm{PH}$.

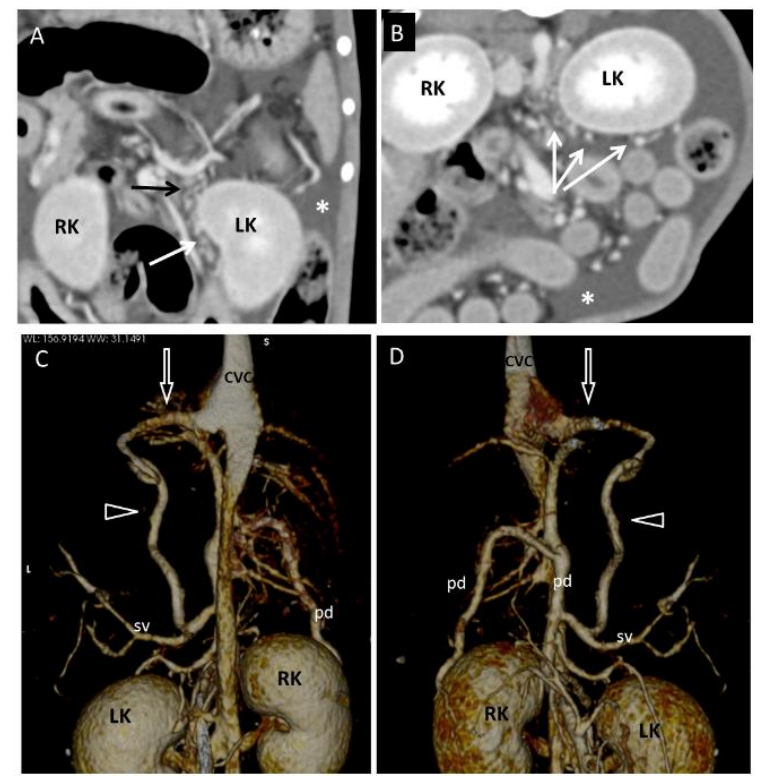

Fig. 7. Dog 2 of PH group. (A) Dorsal and (B) transverse multiplanar reformatted CT images of abdomen at level of kidneys. Gastrophrenic varices (long arrows) are visible medially and ventrally to the left kidney (LK). Large amount of fluid (ascites) is evident in background (asterisks). (C) Dorsal and (D) ventral three-dimensional volume-rendered CT angiography of portal system and caudal vena cava. A splenophrenic PSS (arrowheads) connects splenic vein (sv) and caudal vena cava (CVC) at level of insertion of phrenic vein (empty arrows). RK, right kidney; PV, portal vein; pd, pancreaticoduodenal vein.

Unfortunately the retrospective nature of this study did not allowed to demonstrate this eventuality in the three patients of CPSS group having a single splenophrenic shunt without ascites, due to the lack of liver histopathology. However, in the author's opinion, this eventuality would deserve to be considered in further studies. It has been demonstrated that the development of ascites in humans is inconstant or uncommon in major diseases showing $\mathrm{PH}$ such as cirrhosis (incidence of ascites: $50 \%$ ) and idiopathic portal hypertension (IPH) (incidence of ascites: 10\%) (Gines et al., 1987; Sarin and Kapoor, 2002; Sarin et al., 2007). Furthermore, one study on congenital and acquired PSS in dogs showed a prevalence of $45 \%$ for ascites in patients with APSS (Adam et al., 2012). Actually, among CTA of dogs with $\mathrm{PH}$ reviewed in this paper, only one imaging findings was shared: the presence of 
more than one porto-caval vascular connections. In seven out of 9 cases multiple large shunt and varices were found. One out of 9 dogs had only varices and one out of 9 had two large PSS and severe hepatic structural disorder (diffuse hepatic neoplasia). Although considered a rare phenomenon, multiple CPSS have also been described in dogs (Johnson et al., 1987; Wilson et al., 1997; Morandi et al., 2005; Leeman et al., 2013); in all cases however, large porto-caval or porto-azygous vascular connections were reported without varices. Also, in the author's opinion, the possibility that dogs 1 and 2 of PH-group had all CPSS (including the splenophrenic) is considered less likely because the majority of the PSS patterns found in these dogs were codified in (and seemed typical of) different classifications of MAPSS (Bertolini, 2010a; Ricciardi et al., 2014) (Table 2 - dogs 1 and 2). Furthermore, it would be unlikely that multiple CPSS (even large ones) are all together (i.e. working simultaneously) insufficient to alleviate $\mathrm{PH}$, so that ascites would develop, like in our dogs 1 and 2.

Finally, from an anatomical point of view, besides splenophrenic shunt, several unclassified patterns of large porto-caval vascular connections were observed in the group of dogs with PH (Table 2, asterisks). They connected various portal branches (eg. Splenic vein, pre-hepatic portal branches, pancreaticoduodenal vein) with caval circulation at different points, such as right gonadal vein (Fig. 1), main trunk of caudal vena cava (Fig. 4) or even cranial vena cava via internal thoracic veins (Fig. 3). These PSS have never been previously classified among APSS but in our cases they were considered acquired portal collaterals because they were associated with ascites, other porto-caval connections, and a confirmed cause of PH.

In summary, the results of this study corroborate two hypotheses: 1) acquired and congenital PSS may share the same anatomical pattern of porto-caval connection (in the case of splenophrenic pattern). Hence large shunts previously classified as congenital may be expected in patients with $\mathrm{PH}$ or, otherwise, 2) in the same dog with $\mathrm{PH}$, large portal collaterals and splenophrenic PSS, we can consider the possibility of the coexistence of APSS and CPSS.

PSS pattern and the presence or absence of ascites did not permit in any case differentiation between congenital vascular disease and acquired portal collaterals secondary to PH. Indeed, the number of PSS (single vs. multiple porto-caval connections), presence/absence of varices and macroscopic structural cause of portal flow disturbance seem to be more useful in distinguishing congenital from acquired conditions. This study is limited by the scarcity of dogs examined due to the low incidence of such vascular diseases. Further studies are needed in order to evaluate if other PSS patterns, besides splenophrenic, may be found as both congenital and acquired vascular disorders and to correlate them with other signs of $\mathrm{PH}$, such as ascites. Lastly, from the analysis of APSS in the group of dogs with $\mathrm{PH}$, three new anatomical patterns of acquired porto-caval connection were seen:

1) portal vein - right gonadal vein;

2) portal vein - caudal vena cava (main trunk);

3) portal vein-left internal thoracic vein.

\section{Conflict of Interests}

The Author declare that there is no conflict of interest.

\section{Acknowledgments}

The authors wish to thank all the staff of the "Pingry" Veterinary Hospital of Bari, Italy for their assistance with data collection.

\section{References}

Adam, F.H., German, A.J., McConnell, J.F., Trehy, M.R., Whitley, N., Collings, A., Watson, P.J. and Burrow, R.D. 2012. Clinical and clinicopathologic abnormalities in young dogs with acquired and congenital portosystemic shunts: 93 cases (20032008). J. Am. Vet. Med. Assoc. 241, 760-765.

Agg, E.J. 2006. Acquired extrahepatic portosystemic shunts in a young dog. Can. Vet. J. 47, 697-699.

Bertolini, G. 2010a. Acquired portal collateral circulation in the dog and cat. Vet. Radiol. Ultrasound. 51, 25-33.

Bertolini, G. 2010b. MDCT for abdominal vascular assessment in dogs: MDCT basics, CTangiography, normal anatomy and congenital anomalies. LAMBERT Academic Publishing, Saarbrucken, Germany.

Bertolini, G., Rolla, E.C., Zotti, A. and Caldin, M. 2006. Three-dimensional multislice helical computed tomography techniques for canine extrahepatic portosystemic shunt assessment. Vet. Radiol. Ultrasound. 47, 439-443.

Bruehschwein, A., Foltin, I., Flatz, K., Zoellner, M., Matis, U. 2010. Contrast-enhanced magnetic resonance angiography for diagnosis of portosystemic shunts in 10 dogs. Vet. Radiol. Ultrasound. 51, 116-121.

Bunch, S.E., Johnson, S.E. and Cullen, J.M. 2001. Idiopathic noncirrhotic portal hypertension in dogs: 33 cases (1982-1998). J. Am. Vet. Med. Assoc. 218, 392-399.

Buob, S., Johnston, A.N. and Webster, C.R. 2011. Portal hypertension: pathophysiology, diagnosis, and treatment. J. Vet. Intern. Med. 25, 169-186.

Center, S.A. 1996. Hepatic Vascular Diseases, In: Strombeck's Small Animal Gastroenterology. $3^{\text {rd }}$ ed. W.B. Saunders Company, Philadelphia, pp: 802-846.

Ferrell, E.A., Graham, J.P., Hanel, R.S., Randell, S., Farese, J.P. and Castleman, W.L. 2003. Simultaneous congenital and acquired extrahepatic 
portosystemic shunts in two dogs. Vet. Radiol. Ultrasound. 44, 38-42.

Fossum, T.W. 2002. Small Animal Surgery, $2^{\text {nd }}$ ed., Mosby, St. Louis, pp: 457-468.

Fukushima, K., Kanemoto, H., Ohno, K.M., Takahashi, R., Fujiwara, R., Nishimura, R. and Tsujimoto, H. 2014. Computed tomographic morphology and clinical features of extrahepatic portosystemic shunts in 172 dogs in Japan. Vet. J. 199, 376-381.

Gines, P., Quintero, E., Arroyo, V., Terés, J., Bruguera, M., Rimola, A., Caballería, J., Rodés, J. and Rozman, C. 1987. Compensated cirrhosis: natural history and prognostic factors. Hepatology 7, 122128.

Hunt, G.B. 2004. Effect of breed on anatomy of portosystemic shunts resulting from congenital diseases in dogs and cats: a review of 242 cases. Aust. Vet. J. 82, 746-749.

Huntington, G.S. and Mcclure, C.F.W. 1920. The development of the veins in the domestic cat (Felis domestica) with especial reference, (1) to the share taken by the supracardinal veins in the developmentof the postcava and azygos veins and (2) to the interpretation of the variant conditions of the postcava and its tributaries as found in the adult. Anat. Rec. 20, 1-30.

Johnson, C.A., Armstrong, P.J. and Hauptman, J.G. 1987. Congenital portosystemic shunts in dogs: 46 cases (1979-1986). J. Am. Vet. Med. Assoc. 191, 1478-1483.

Kraun, M.B., Nelson, L.L., Hauptman, J.G. and Nelson, N.C. 2014. Analysis of the relationship of extrahepatic portosystemic shunt morphology with clinical variables in dogs: 53 cases (2009-2012). J. Am. Vet. Med. Assoc. 245, 540-549.

Lamb, C.R. 1996. Ultrasonographic diagnosis of congenital portosystemic shunts in dogs: Results of a prospective study. Vet. Radiol. Ultrasound. 37, 281-288.

Leeman, J.J., Kim, S.E., Reese, D.J., Risselada, M. and Ellison, G.W. 2013. Multiple congenital PSS in a dog: case report and literature review. J. Am. Anim. Hosp. Asso. 49, 281-285.

Morandi, F., Cole, R.C., Tobias, K.M., Berry, C.R., Avenell, J. and Daniel, G.B. 2005. Use of 99mTCO4(-) trans-splenic portal scintigraphy for diagnosis of portosystemic shunts in 28 dogs. Vet. Radiol. Ultrasound. 46, 153-161.

Nelson, N.C. and Nelson, L.L. 2011. Anatomy of extrahepatic portosystemic shunts in dogs as determined by computed tomography angiography. Vet. Radiol. Ultrasound. 52, 498-506.

Ricciardi, M., Martino, R. and Assad, E.A. 2014. Imaging diagnosis--celiacomesenteric trunk and portal vein hypoplasia in a pit bull terrier. Vet. Radiol. Ultrasound. 55, 190-194.

Sarin, S.K. and Kapoor, D. 2002. Non-cirrhotic portal fibrosis: current concepts and management. J. Gastroenterol. Hepatol. 17, 526-34.

Sarin, S.K., Kumar, A., Chawla, Y.K., Baijal, S.S., Dhiman, R.K., Jafri, W., Lesmana, L.A., Guha Mazumder, D., Omata, M., Qureshi, H., Raza, R.M., Sahni, P., Sakhuja, P., Salih, M., Santra, A., Sharma, B.C., Sharma, P., Shiha, G. and Sollano, J. 2007. Noncirrhotic portal fibrosis/idiopathic portal hypertension: APASL recommendations for diagnosis and treatment. Hepatol. Int. 1, 398413.

Szatmári, V. 2003. Simultaneous congenital and acquired extrahepatic portosystemic shunts in two dogs. Vet. Radiol. Ultrasound. 44, 486-487.

Szatmari, V. and Rothuizen, J. 2002. How can you tell with ultrasound that a patient with high blood ammonia has a congenital or acquired portosystemic shunt or no shunt at all? In the Proceedings of the $27^{\text {th }}$ Congress of the World Small Animal Veterinary Association, October 3-6, Granada, Spain, pp: 42.

Szatmàri, V., Rothuizen, J., van den Ingh, T.S., van Sluijs, F. and Voorhout, G. 2004. Ultrasonographic findings in dogs with hyperammonemia: 90 cases (2000-2002). J. Am. Vet. Med. Assoc. 224, 717727.

Van den Ingh, T.S., Rothuizen, J. and Meyer, H.P. 1995a. Circulatory disorders of the liver in dogs and cats. Vet. Q. 17, 70-76.

Van den Ingh, T.S., Rothuizen, J. and Meyer, H.P. 1995b. Portal hypertension associated with primary hypoplasia of the hepatic portal vein in dogs. Vet. Rec. 137, 424-427.

Watson, P.J. and Herrtage, M.E. 1998. Medical management of congenital portosystemic shunts in 27 dogs - a retrospective study. J. Small Anim. Pract. 39, 62-68.

Wilson, K., Scrivani, P. and Léveillé, R. 1997. Veterinary medicine today "What is your diagnosis?”. J. Am. Vet. Med. Assoc. 21, 415-416.

Wrigley, R.H., Konde, L.J., Park, R.D. and Lebel, J.L. 1987. Ultrasonographic diagnosis of portacaval shunts in young dogs. J. Am. Vet. Med. Assoc.191, 421-424. 